\title{
Field Research and Development of Plant Growth Regulators by the Agrochemical Industry
}

\author{
Craig A. Campbell
}

Additional Index wORDs. tertiary amine, sugar accumulation, Brix, PGR, MBTA, EcoLyst, PGR development

Summary. This paper describes the field research and development (FRD) process followed by agrochemical companies when developing a new plant growth regulator (PGR). Specific approaches used by Valent BioSciences Corporation in developing EcoLyst, a newly registered PGR for use on orange (Citrus sinensis) in the United States, are cited as examples of this process. Agrochemical companies acquire some new PGR compounds from outside sources, while others are discovered internally. Internal development of new compounds is simpler to control and manage. When a new PGR is identified from an outside source, a company must first determine if the compound is available for licensing or outright purchase. If so, they assemble a team of internal experts to review all available data (due diligence) to determine if it has sufficient value to warrant pursuit. Once a PGR passes the initial screening processes and is approved for acquisition and potential development, negotiations begin with the owner of the compound. Many projects stop abruptly when the negotiating companies fail to reach an agreement. Immediately after an agrochemical company successfully acquires a new PGR, a well-coordinated chain of events is initiated throughout the company's organization to accelerate work on the project. One component of this involves the FRD team, which creates a comprehensive field research plan for the PGR containing clearly defined development goals that are global in scope. The FRD team works throughout the world, near important crop production areas, conducting research with the company's products. Members of the FRD team generally report to a research leader located at the company's main headquarters. The FRD team is one part of a larger development team, that works collectively to find and develop promising new compounds and new uses for existing company products. If initial research results from a new compound are favorable, the objectives of the workplan increase significantly after the first year. University and government researchers are generally brought into the research programs after a year or two of in-house testing. Early stage work is often done under a secrecy agreement in order to protect proprietary information and interests. Specific control points are identified in the development process, where decisions are made to continue or not, based on reviews of research data, business plans, and regulatory progress.

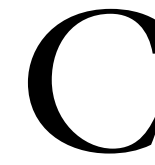

ompanies that develop and register new plant growth regulators (PGRs) usually have a team of field research scientists who work in a highly coordinated manner with the rest of the development team to take what may be little more than a good idea, and turn it into a agricultural product ready for use by growers. Things are likely to go wrong along the way, even with the best technology, making control points and a clear development plan crucial for success.

Effective field research and development (FRD) for a new PGR can be compared to a traveler on a long journey, who first determines where he/she wants to be at the journey's end. The traveler then does some background research, plots a course carefully, establishes achievable milestones, and stops periodically to assess progress and proper direction. The FRD team also establishes milestones for its projects, and then conducts research to determine if the goals are attainable. The types of experiments used depend on the intended use for the new PGR and the $\operatorname{target} \operatorname{crop}(\mathrm{s})$. 


\section{How companies acquire new PGRs}

Although acquisition efforts for new agricultural products vary greatly among companies, a few general procedures are common to programs seeking new PGR compounds. Due diligence is the name generally used for the process of reviewing all the available information on a new compound. Theinterested companyneeds to fairly assess the potential for a new PGR by identifying the compounds inherent strengths and weaknesses. In addition to published information, unpublished research reports, company memoranda, and discussions with scientists and managers hold great value in the due-diligence process. A company's marketing department is generally called upon to assess the domestic or global market potential for an acquisition prospect, using the research results gleaned during due-diligence reviews. The report on market potential is then used to estimate the potential sales value for a new PGR based on a product lifespan of 10 to 20 years or more.

A regulatory assessment must also be made of a new compound to determine the complexity and potential cost of the research needed to obtain approval for its use on desired crops in the United States, and in other countries. Expert consultants and computer software programs are often used to facilitate these reviews. Computer programs are used to compare the new compound with compounds of similar structure that already have a registration for use on the crops of interest.

After an agrochemical company decides that it wants to acquire a new PGR, legal advisors and top managers negotiate with the owners of the compound to create a contract or agreement that transfers ownership to the agrochemical company. Thisprocessoftentakesmanymonths as the two sides work out differences regarding the terms of the sale or business agreement. In the case of EcoLyst, Valent BioSciences Corporation (VBC; Libertyville, Ill.) signed a business agreement with another company that gave VBC the rights tocommercialize the product in citrus. VBC also became responsible for manufacturing, sales, and research and development on new crops. EcoLyst is the trade name for $\mathrm{N}, \mathrm{N}$ diethyl-2-(4methylbenzyloxy) ethylamine hydrochloride (MBTA), a tertiary amine compound demonstrated to improve plant growth in ways similar to the tertiary amine $\mathrm{N}, \mathrm{N}$ diethylaminoethyl3,4-dichlorphenylether (DCPTA) (Keithly et al., 1991a, 1991b;
Keithly and Yokoyama, 1992). These tertiary amines were subsequently patented in 1994 by researchers at the U.S. Department of Agriculture as bioregulators to improve plant growth and development (Yokoyama et al., 1994). All the available research data about EcoLyst were turned over to VBC for due-diligence review after the signing of a secrecy agreement. VBC was made aware that the U.S. Environmental Protection Agency(EPA)wasclose to approving a registration for EcoLyst on citrus. EcoLyst was indeed approved for use on orange by the EPA and state of Florida in early 2000, soon after it was taken over by VBC. Other state registrations are pending or under consideration, and additional crop uses are currently being researched. The company that licensed the compound to VBCspent nearly 10 years, and millions of dollars, conducting research to obtain the EPA registration.

\section{Field development of the new compound}

The FRD process for a new PGR commences rapidly after a successful acquisition, as it does when an internal compound is determined to be ready for field development. The desire to recover expenses from exploratory research, or from the purchase of a new PGR, makes time of the essence in a development program. It is the FRD program that will yield information on the new compound's activity and grower value that is a critical part of the future success of the project. The FRD team prepares a part of the comprehensive development plan that guides the budding new compound into the marketplace and a successful introduction, which is typically called a launch. The marketing or business development unit is generally the group responsible for conducting market assessment studies to determine if the resulting agrochemical product can adequately satisfy the needs of crop producers. Will the new product provide growers a favorable return on theirinvestment? Are there cheaper alternatives? Can the product be used on a large number of crops? Will the product fit into grower's production systems. Should market assessments show little potential for a new compound, development programs may be redirected or terminated. Favorable market assessments, on the other hand, take a development program past another checkpoint. After the development team decides upon a group of crops and regions, the lists are prioritized and allocated to research teams in laboratories and in the field. The most comprehensive debates generally involve research priorities, resource allocations, and potential crops for a new PGR.

Most FRD teams have scientists that specializein particularcrops, types of products (PGRs, fungicides, insecticides, etc.), or geographical areas. During their career individual FRD scientists develop relationships with a broad range of university and government scientists, as well as research contractors, with whom they conduct cooperative research projects. Experiments are carried out in many settings, from research plantings designed for this purpose, to commercial farms with cooperating growers. Agrochemical companies often sponsor such research with grants. Although some companies have reservations about research collaboration and idea sharing, many FRD scientists enjoy working with cooperators on interesting new projects, interacting with other researchers, and participating actively at scientific meetings. They may view these things as a vital part of their career development.

When developing a new PGR, some experienced companiesuseaconceptwhere the development group attempts to describe in detail what an ideal new agrochemical product would be like. VBC described the ideal EcoLyst product as highly effective all the time, easy to use, stable in hot and cold climates, attractively packaged, safe for applicators and the environment, profitable, and resistant tocompetition. After the ideal product is described, the idea is to design a research and development plan that molds the new compound to fit as many of the descriptors as possible, in the least amount of time. Responsibility for designing individual experiments to explore the activity of the new PGR can be left to individual scientists, as is the case at VBC. Other companies complete this step by committee, and then assign researchers to complete trials in the individual territories. Common experiments in the early stages of the FRD program test the new PGR at varying rates and application times. Sometimes the mechanism of action, plant target of greatest response, or best phenological stage for application must also be determined.

VBC had compelling research evidence showing that when EcoLyst was sprayed on orange trees during the spring bloom and vegetative flush, sugar accumulation increased in the fruits during maturation (Campbell et al., 1999). Despite this evidence, the companyneeded to verify the effects of EcoLyst on soluble solids content (Brix) of orange in large 
demonstration trials that would also give growers exposure to the product. Largescale trials were initiated across Florida's citrus growing region with companies growing 'Hamlin' and 'Valencia' orange for the juice market. In additional to the commercial trials, VBC also conducted replicated experiments, focusing primarily on application rate and timing, with scientists at the University of Florida. Yearly reviews of the research results allow the company to assess development progress and prepare a revised research plan.

At VBC, once FRD programs are initiated, progress is measured using predetermined goals. Formal control points are established at annual meetings where go or no-go decisions are made for the projects. At these periodic evaluations, projects are often accelerated due to promising results. Conversely, sometimes it is necessary to revise or terminate projects and change research direction. In general, the earliest stages of FRD programs are conducted exclusively by company scientists. Once sufficient progress has been made to define a basic product profile, VBC begins working with university and government researchers on a PGR project. Collaboration with scientists outside the company often brings new ideas to the program. A successful PGR development project registers the new compound and proves it useful to the agrochemical company's primary customers, the crop producers.

Testing of anew compound to determine its impact on the environment and nontarget organisms is required by the EPA(orregulatoryagenciesin othercountries) as part of the registration and approval process for a new agrochemical product. Specialized researchers that work independent of, but in concert with, the FRD teams generally complete this work under contract to the agrochemical company. FRD scientists are often involved, however, in residue testing. Residue testing is required by the EPA for new agrochemical products whereby the product is applied at specific concentrations to the crops under consideration. The crops are harvested atspecificintervals after the PGR application, and then tested for the presence of residues and breakdown products of the applied compound. All data submitted to the EPA for registration of a new compound must be obtained using studies conducted in accordance with federal standards called Good Laboratory Practices(GLP). The researcher mustalso have received GLP training.

A highly successful program that as- sists growers of minor crops who need additional pest management solutions is the Interregional Research Project \#4 (IR4), based at Rutgers University in New Jersey. The purpose of the program is to help get agrochemicals registered in the United States on minor crops, as many companies are slower to pursue these registrations [ 300,000 acres $(121,410 \mathrm{ha})$ or less in U.S. production]. The IR-4 program is a good example of cooperation betweenagrochemical companies, research institutions, growers, and the EPA.

An agrochemical company normally tests numerous product formulations as FRD programs advance for a new compound. The PGR is tested in combination with various adjuvants that may increase its activity. The new product is also tested in combination with other appropriate agricultural products, to provide growers with compatible materials for tank-mixing to reduce application costs. Throughout product testing, but especially in the early stages, field scientists must watch for unexpected plant responses to the PGR. This concept goes well beyond phytotoxicity. Unanticipated results, which may range from beneficial to devastating, are often subtle and difficult to measure without repeated experiments or multiyearstudies, but recognizing subtle effects from a new compound can greatly enhance itsvalue to growers and the agrochemical company.

FRD projects involving PGRs can be hindered because some active ingredients are poorly understood. In addition, measuring multiple plant responses to an applied PGR is laborious and time consuming, particularly since research data on PGRs becomes out-of-date as cultivars and production systems change. Companies want reliable research results in the shortest time possible, and seldom allow FRD teams the many years necessary to make an exhaustive evaluation of a new PGR compound. Scientists working for agrochemical companies are required to balance their research activities with the company's commercial goals. A great deal of an FRD scientist's time may also be spent conducting extension activities for company products, by educating distributors, sales people, researchers, and growers. As such, research results from company scientists are occasionally criticized as being unfairly biased. Agrochemical companies understand, however, that it only makes sense to base important business decisions on sound, unbiased research.

\section{Conclusions}

From the beginning of a project with a new PGR compound, research results tend to dictate the rate of progress to the final goal of a registered product that is used and valued by growers. Business decisions depend upon the outcome of registration trials and field efficacy experiments. Decisions regarding target crops are difficult for most companies. Attempting to register the PGR on too few crops can limit its growth and adoption by growers, whereas attempting to label the product too broadly can also prevent success by draining limited resources. Field research results form an important part of the framework for designing registration trials, and are the basis for product recommendations to growers. Research data are routinely brought together for study by the company, and for inclusion in registration packagessubmitted to EPA and agenciesin other countries. The EPA may grant experimental use permits that allow limited commercial testing of a product before it is officially registered. Agrochemical companies must be highly organized to keep development projects on track, constantly looking for gaps in their research that could delay registration, or complicate product use after its sale to crop producers. After the registration for the new PGR is granted, the product is sold to growers, which begins a new phase of research where the compound isstudied in a much broader sense, and hopefully improved, while being used commercially. For all these reasons, rigorous research standards and a high level of organization are required to successfully develop a new PGR in the agrochemical industry.

\section{Literature cited}

Campbell, C.A., T. Taggart, and J. Keithly. 1999. A novel plant growth regulator, MBTA, increases soluble solids (Brix) of 'Valencia' orange. Proc. Fla. State Hort. Soc. 112:25-28.

Keithly, J., H. Kobayashi, and H. Yokoyama, 1991. Enhanced vegetative growth and development of processing tomato by DCPTA treatment of seed. J. Amer. Soc. Hort. Sci. 116(4):693-696.

Keithly, J., H. Yokoyama, and H. Gausman. 1991. Regulation of crop growth and yield by tertiary amine bioregulators, p. 223-247. In:H. Gausman(ed.). Plant biochemical regulators. Marcel Dekker, New York.

Keithly, J., and H. Yokoyama. 1992. Promotive effects of DCPTA on seedling development and growth of radish. J. Amer. Soc. Hort. Sci. 117(2):294-297.

Yokoyama, H., J. Keithly, and H. Gausman. 1994. New matter of composition and method for using the same as plant bioregulator. United States patent, US005298483A. U.S. Patent and Trademark Office, Wash., D.C. 